\title{
Hydrodynamic Mechanism of Turbidity Currents in Estuary Stratifications
}

Zhiguo He, Ocean College, Zhejiang University, hezhiguo@zju.edu.cn

Liang Zhao, Ocean College, Zhejiang University, liangz@zju.edu.cn

Ching-Hao Yu, Ocean College, Zhejiang University, chyu@zju.edu.cn

\section{ABSTRACT}

Water stratification commonly exists in nature, such as thermocline in lakes and oceans and halocline in estuaries and oceans (He et al. 2017). Turbidity currents in estuary often encounter stratified sea water, which may significantly influence their propagation and deposition. This study presents high-resolution numerical simulations of lock-exchange gravity and turbidity currents in linear stratifications on a flat bed. Laboratory experiments are conducted to validate the numerical model and good agreements between numerical results and measurements are found. The evolution process, front velocity, internal wave, and entrainment ratio are analyzed based on the numerical results. For a gravity current in a strong stratification, its front velocity can be maintained as a near constant state for a long time after an initial acceleration period because of interactions between the current and internal waves. However, sedimentation of suspended particles due to the damping effect of ambient stratification on turbulence makes a turbidity current quickly lose its structure so the maintaining effect of the internal waves on its front velocity is quite weak. During the evolution process of a turbidity current, the ambient stratification is found to damp the turbulent structures, and front velocity. Stratification can also decrease the entrainment ratios between a gravity current and ambient water after the initial period, but it has an insignificant influence on the entrainment ratios of a turbidity current. This study provides a better understanding of gravity and turbidity currents in estuary stratifications.

Figure 1 shows the evolution process of a lockexchange turbidity current in a linear stratification. The typical characteristics, such as the collapse of the dense fluid, the lifted nose, and the Kelvin-Helmholtz instabilities can be well captured by the present model.
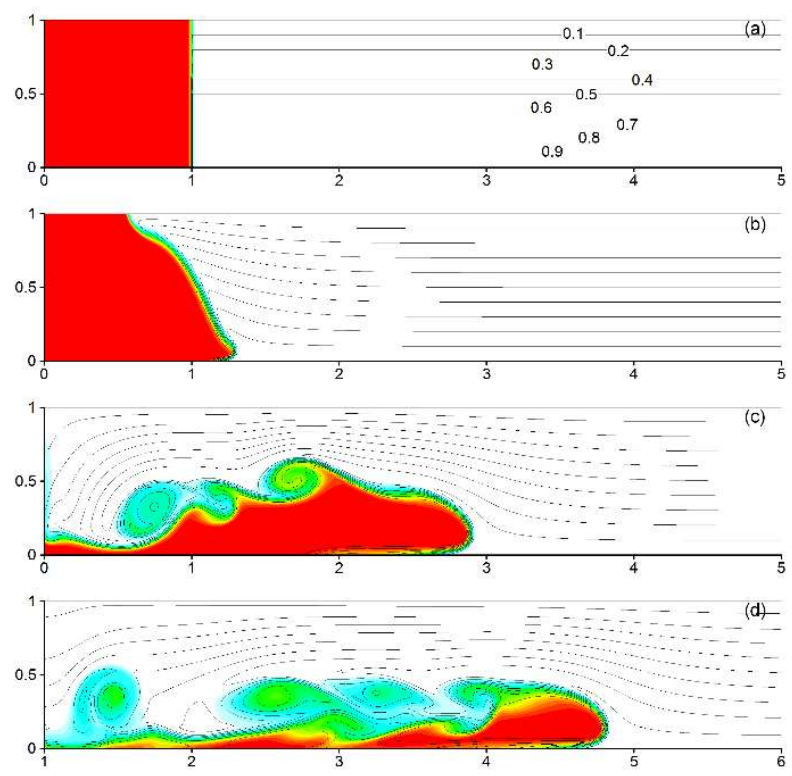

Figure 1 - Evolution process of a lock-exchange turbidity current in a linear stratification. The turbidity current is visualized by the particle concentration. The gray line indicates the nondimensional salinity of the ambient water. (a) $t=0$; (b) $t=1$; (c) $t=5$; (d) $t=10$..

Figure 2 shows turbidity currents in different ambient stratifications at $t=8$. The most significant difference of a turbidity current in a stronger stratification is that the Kelvin-Helmholtz instabilities and turbulent billows at the upper interface are greatly damped.
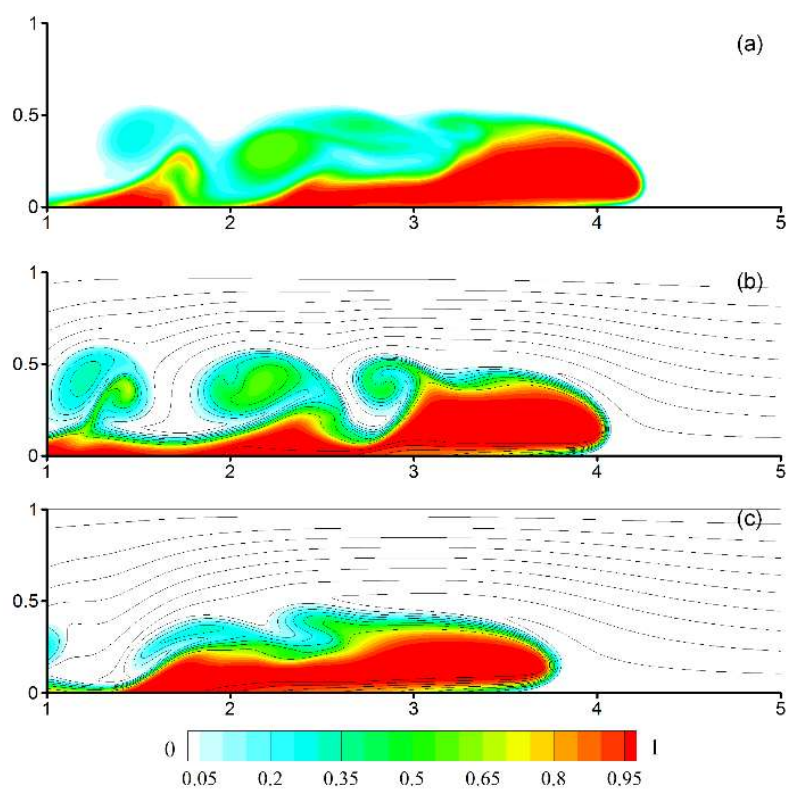

Figure 2 - Turbidity currents in different ambient environments at the same time. (a) Unstratification; (b) Relatively weak stratification; (c) Strong stratification.

\section{ACKNOWLEDGE}

This work was partially supported by the National Natural Science Foundation of China (11672267) and Research Funding of Shenzhen City (JCYJ20160425164642646).

\section{REFERENCES}

He Z, Zhao L, Lin T, Hu P, Lv YF, Ho H, Lin Y (2017): Hydrodynamics of gravity currents down a ramp in linearly stratified environments, Journal of Hydraulic Engineering, ASCE, vol. 143, pp. 04016085. 